Western University

Scholarship@Western

Human Environments Analysis Lab (HEAL)

9-2019

\title{
"Reduce Food Waste, Save Money": Testing a Novel Intervention to Reduce Household Food Waste
}

Paul van der Werf

Western University, pvande2@uwo.ca

Jamie A. Seabrook

Brescia University, jseabro2@uwo.ca

Jason A. Gilliland

Western University, jgillila@uwo.ca

Follow this and additional works at: https://ir.lib.uwo.ca/healpub

Citation of this paper:

van der Werf, P., Seabrook, J. A., \& Gilliland, J. A. (2019). "Reduce Food Waste, Save Money”: Testing a Novel Intervention to Reduce Household Food Waste. Environment and Behavior. https://doi.org/10.1177/ 0013916519875180 
"Reduce Food Waste, Save Money": Testing a Novel Intervention to Reduce Household Food Waste
Environment and Behavior

$1-33$

(C) The Author(s) 2019

Article reuse guidelines: sagepub.com/journals-permissions DOI: $10.1177 / 0013916519875180$ journals.sagepub.com/home/eab

(S)AGE

\title{
Paul van der Werf' ${ }^{1}$, Jamie A. Seabrook ${ }^{2}$, and Jason A. Gilliland'
}

\begin{abstract}
An intervention, which used elements of the theory of planned behavior, was developed and tested in a randomized control trial (RCT) involving households in the city of London, Ontario, Canada. A bespoke methodology involving the direct collection and measurement of food waste within curbside garbage samples of control $(n=58)$ and treatment households $(n=54)$ was used to evaluate the effectiveness of the intervention. A comparison of garbage samples before and after the intervention revealed that total food waste in treatment households decreased by $31 \%$ after the intervention and the decrease was significantly greater $(p=.02)$ than for control households. Similarly, avoidable food waste decreased by $30 \%$ in treatment households and was also significantly greater $(p=.05)$ than for control households. Key determinants of treatment household avoidable food waste reduction included personal attitudes, perceived behavioral control, the number of people in a household, and the amount of garbage set out.
\end{abstract}

\section{Keywords}

household food waste, intervention, waste characterization, theory of planned behavior, avoidable food waste

\footnotetext{
'Western University, London, Ontario, Canada

${ }^{2}$ Brescia University College, London, Ontario, Canada
}

\section{Corresponding Author:}

Paul van der Werf, Department of Geography, Western University, II5I Richmond Street, London, Ontario, Canada N6A 3K7.

Email: pvande2@uwo.ca 
Wasting food results in a confluence of negative monetary, environmental, and social impacts. There is substantial academic and societal interest in finding ways to intervene to reduce food wasting, particularly at the household level. This interest has largely focused on avoidable food waste, which is defined as food that was, at one point, edible: as opposed to unavoidable food waste (e.g., vegetable peels, bones) (Beretta, Stoessel, Baier, \& Hellweg, 2013; Waste \& Resources Action Program [WRAP], 2009). Despite the growing interest, knowledge gaps exist in our understanding of what drives food wasting behavior (Schanes, Dobernig, \& Gözet, 2018; Visschers, Wickli, \& Siegrist, 2016), how to develop effective policies and programs to reduce household food wasting (Hebrok \& Boks, 2017; Schanes et al., 2018), and how to adequately evaluate interventions (Hoj, 2012). The overarching purpose of this study is to develop and pilot test a theoretically informed intervention to reduce household food wasting and to evaluate its effectiveness through a randomized controlled trial (RCT).

\section{The Impacts and Determinants of Household Food Wasting}

It is estimated that up to $50 \%$ of food available for consumption is wasted (i.e., the food waste that is avoidable) along the food supply chain (Gustavsson, Cederberg, Sonesson, Van Otterdijk, \& Meybeck, 2011; Parfitt, Barthel, \& MacNaughton, 2010). As described in a recent systematic review of food waste quantities in developed countries, an estimated $198.9 \mathrm{~kg} / \mathrm{capita} /$ year $(S D=82.3)$ of food waste is generated across the food supply chain, with $114.3 \mathrm{~kg} / \mathrm{capita} /$ year $(S D=68.7)$ generated at the consumer or household level (van der Werf \& Gilliland, 2017). In the United States, the monetary impacts of food waste across the food supply chain are estimated to be US\$166 billion annually; this includes an estimated loss of about $10 \%$ of household food expenditures (Buzby \& Hyman, 2012). Furthermore, the municipal collection and disposal of household food waste also represents an unnecessary cost. Food waste's environmental impacts are considerable and include wasted energy (Cuéllar \& Webber, 2010), wasted water (Lundqvist, de Fraiture, \& Molden, 2008), and greenhouse gas generation from agricultural production and shipment to markets (Agriculture and Agrifood Canada, 2015; Weber \& Matthews, 2008). Wasting food also has indirect social impacts. At the same time that many households throw out food, 14.7 million people in developed countries are undernourished (Food and Agriculture Organization of the United Nations, The International Fund for Agricultural Development, \& World Food Program, 2015). In Canada, 8\% of adults live in food insecure households (Statistics Canada, 2015). 
The development of successful food waste reduction interventions at the household level needs to begin with an understanding of who wastes food and why. Researchers have identified sociodemographic determinants, including age (especially households with younger children; Fusions, 2014; Melbye, Onozaka, \& Hansen, 2017; Tucker \& Farrelly, 2016), household size and type (i.e., larger and with children; Baker, Fear, \& Denniss, 2009; Koivupuro, Hartikainen, Silvennoinen, Katajajuuri, \& Heikintalo, 2012; Neff, 2015; Parizeau, von Massow, \& Martin, 2015), higher household income (Fusions, 2014; Neff, 2015; Stancu, Haugaard, \& Lahteenmaki, 2016), and gender (with males potentially wasting more than females; Koivupuro et al., 2012; Secondi, Principato, \& Laureti, 2015; Visschers et al., 2016).

Research has identified several other reasons why household food is wasted, including spoilage (i.e., food that has decayed), fussy eaters in the household, or being overly sensitive to high-risk food spoilage (Göbel, Langen, Blumenthal, Teitscheid, \& Ritter, 2015; Halloran, Clement, Kornum, Bucatariu, \& Magid, 2014; Jorissen, Priefer, \& Brautigam, 2015; Thyberg, Tonjes, \& Gurevitch, 2015). These determinants can be placed under the umbrella of poor "food literacy," which is defined as a lack of knowledge regarding the various aspects of household food management, which encompasses the planning, buying, preparing, serving, and storing of food (Altman \& Gardner, 2000). Food literacy also includes confusion regarding food labels such as "best before" and "use by" dates (Porpino, 2016; Principato, Secondi, \& Pratesi, 2015; WRAP, 2011, 2014); inadequate meal planning and grocery shopping (Abeliotis, 2014; Pearson, Minehan, \& Wakefield-Rann, 2013; WRAP, 2011); buying, preparing, and serving too much food (Van Garde \& Woodburn, 1987; WRAP, 2007; Williams, Wikstrom, Otterbring, Lofgren, \& Gustafsson, 2012); poor food storage (Aschemann-Witzel, de Hooge, Amani, Bech-Larsen, \& Oostindjer, 2015; BIO Intelligence Service, 2011; Koivupuro et al., 2012); and what to do with leftovers (Evans, 2012; Graham-Rowe, Jessop, \& Sparks, 2014; WRAP, 2013b).

\section{Intervention Development Prerequisites}

The development of an effective intervention needs to not only consider the key determinants of household food wasting such as household sociodemographic characteristics and food literacy, but also an understanding of what factors might motivate households to reduce food waste, as well as behavioral determinants.

Food waste reduction motivators. The strongest potential food waste reduction motivators appear to be saving money (Abeliotis, 2014; Porpino, 2016; 
Tucker \& Farrelly, 2016) and moral values (Bolton, 2012; Graham-Rowe et al., 2014; Neff, 2015; Quested, Marsh, Stunell, \& Parry, 2013, van der Werf, Seabrook \& Gilliland, 2019). For instance, the financial impacts of purchasing too much food is a driver that can reduce food waste (GrahamRowe et al., 2014; Quested et al., 2013; Williams et al., 2012). Much weaker motivators appear to be concerned about the environmental impact of food waste (BIO Intelligence Service, 2011; Neff, 2015; Quested et al., 2013; Tucker \& Farrelly, 2016; Watson \& Meah, 2012) and humanitarian (i.e., social) concerns, such as hunger and poverty (Baker et al., 2009; Tucker \& Farrelly, 2016; Watson \& Meah, 2012). Health-conscious consumers appear to be motivated to reduce food waste (Quested et al., 2013), although these consumers typically buy more perishable commodities, some of which were ultimately discarded (Evans, 2011; Graham-Rowe et al., 2014). Stancu et al. (2016) reported that people were more aware of the economic consequences than environmental and social consequences, suggesting that "people are motivated . . . by self-interest in their food waste behavior" and that they see food waste behavior as food-related behavior, and much less so as an environmental behavior (p. 16).

Food waste behavioral determinants. Several studies of behavioral determinants of food wasting have used the theory of planned behavior (TPB; Ajzen, 1991) for a conceptual framework and have focused on the key antecedents including intention, attitudes, subjective norms, and perceived behavioral control, as well as how intention influences behavior.

Previous studies have shown that consumers feel "bad" or were otherwise concerned about throwing away food and this informs a negative attitude toward this behavior (Abeliotis, 2014; Evans, 2012; Graham-Rowe et al., 2014; Graham-Rowe, Jessop, \& Sparks, 2015; Thyberg \& Tonjes, 2016; Watson \& Meah, 2012). Financial, environmental, social, and health attitudes also influence food wasting behavior, possibly functioning as motivators.

People's behaviors can be influenced by society's expected behavior or subjective norms whether in the context of TPB (Graham-Rowe et al., 2015) or otherwise (Bernstad, 2014; Cappellini, 2009; Cappellini \& Parsons, 2012). This can extend to personal norms or expectations people hold for themselves, and can be driven by moral values (Graham-Rowe et al., 2014; Principato et al., 2015; Secondi et al., 2015; Stancu et al., 2016; WRAP, 2011; Watson \& Meah, 2012) or guilt (Graham-Rowe et al., 2014; Jagau \& Vyrastekova, 2017; Parizeau et al., 2015; Quested et al., 2013; Watson \& Meah, 2012), environmental and civic concerns (Melbye et al., 2017; Principato et al., 2015; Williams et al., 2012), or anticipated regret (Graham-Rowe et al., 2015). Studies by Graham-Rowe et al. (2015) and Stefan, van Herpen, Tudoran, and 


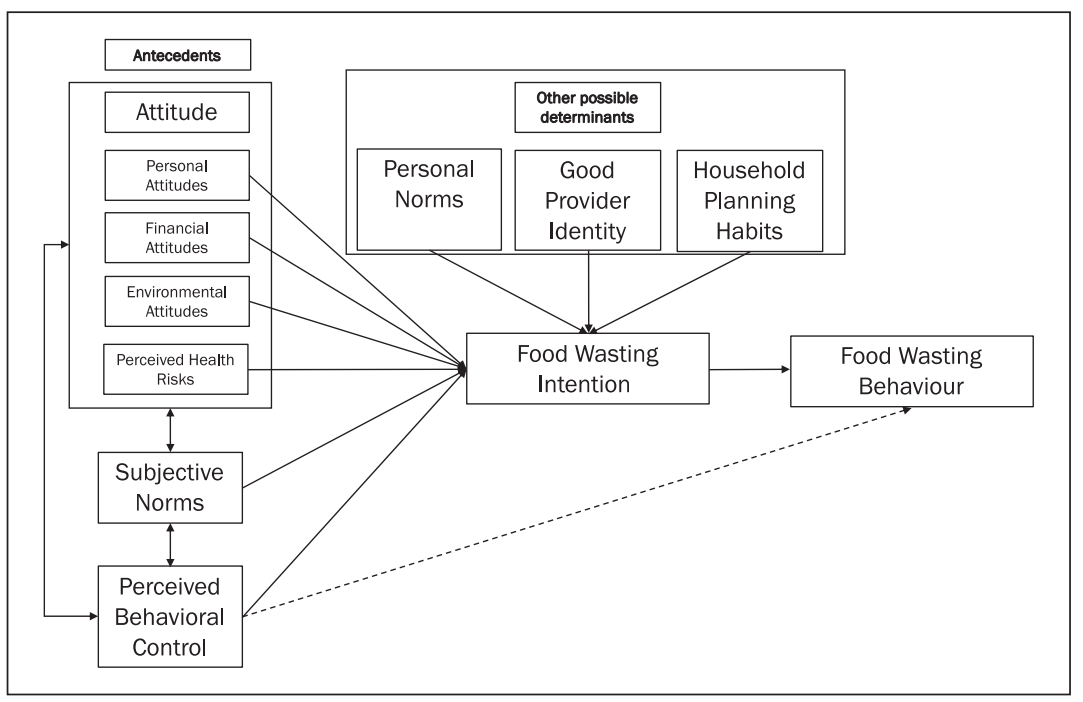

Figure I. Theory of planned behavior and other possible determinants model (Ajzen, 1991; Visschers, Wickli, \& Siegrist, 2016).

Lähteenmäki (2013) both reported that subjective norms were unrelated to food wasting behavior and only modestly influenced intention. This may be because the wasting of food is a behavior that is generally only seen by the generator; therefore, these norms play a reduced role compared with more visible activities (Quested, Parry, Easteal, \& Swannell, 2011).

Perceived behavioral control can function as a strong (Graham-Rowe et al., 2015) or weak (Stancu et al., 2016; Stefan et al., 2013) antecedent of intention, but also a similar, if not stronger, determinant of food wasting behavior (Stancu et al., 2016; Stefan et al., 2013; van der Werf, Seabrook, \& Gilliland, 2019; Visschers et al., 2016). This is in line with the expanded model of TPB (Figure 1) that acknowledges perceived behavioral control's possible influence on behavior. van der Werf et al. (2019) goes so far as to suggest that perceived behavioral control could be exchanged with intention as the key TPB determinant of this behavior. Researchers have also explored other food wasting determinants such as personal norms, household planning habits and the "good provider" identity, which can be manifest by needing to have plenty of food on hand for various expected and unexpected situations (Evans, 2011; Visschers et al., 2016).

There have also been some challenges with the ability of intention to strongly predict food wasting behavior (Russell, Young, Unsworth, \& 
Robinson, 2017; Stancu et al., 2016; Stefan et al., 2013), which may speak to a potential disconnection between people's intention to not waste food and the amount of food they actually waste. A possible reason is that people do not purchase food with the intention of throwing it out, and this is reflected in typically strong survey responses related to the intention to not waste food (van der Werf et al., 2019; Visschers et al., 2016).

The concept of "implementation intention" provides additional insight for understanding food wasting behavior Gollwitzer (1999). An implementation intention is a self-regulatory strategy for goal attainment that involves a plan on how and when to convert intention to behavior. People without implementation intentions are less likely to achieve their behavioral goal than those who have formed implementation intentions. The opportunity to efficaciously act out one's behavioral goal is often fleeting. For instance, holding onto a wrinkled, but edible red pepper, a person is faced with a quick decision: Does this look edible or does this go into the garbage? A person who has formed an implementation intention will have educated themselves to know that they can chop this red pepper up and put it in an omelet or sauce, act accordingly, and meet their behavioral goal. The formation of implementation intentions allows people to switch from effortful control to being automatically controlled by situational cues (Gollwitzer, 1999). Finally, the reason may be something even more fundamental. Seebauer, Fleiß, and Schweighart (2017) note that a household is not an individual, and conversely, an individual survey respondent may not be able to accurately assess household intention and behavior.

Thus, perceived behavioral control may be a better predictor of food wasting behavior and may strengthen the efficacy of the intention-behavior relationship (Graham-Rowe et al., 2015; Schanes et al., 2018; Stancu et al., 2016; van der Werf et al., 2019). Therefore, strengthening perceived behavioral control should be a critical component of intervention development.

\section{Previous Food Waste Reduction Interventions}

In an extensive review of research on household food waste and intervention points, Hebrok and Boks (2017, p. 390) note that "food waste can be seen as a process where food turns to waste, within a web of interrelated practices, tools, concerns, skills, knowledge and anxieties." They identify information and awareness, technology and planning, leftovers and portioning, storage, packaging, food risk, and policy and regulation as possible interventions and/ or intervention insertion points. Still, the development of household food waste reduction interventions is relatively new and the best approach(es) continue to evolve. 
Household food waste reduction can be physically and/or technologically facilitated through creative methods such as (a) the use of intelligent fridges (i.e., refrigerators), which inform and remind users by sending them messages about the state of the food inside by, for instance, using a FridgeCam (Ganglbauer, Fitzpatrick, \& Comber, 2013); (b) modifying the nature or size of packaging to better preserve what is inside it (Verghese, Lewis, Lockrey, \& Williams, 2015); and (c) by using reduced packaging sizes to sell consumers a quantity of food that can be reasonably consumed before it becomes food waste (Evans, 2011). Despite these creative options, information and awareness interventions appear to be the default method used to reduce food waste (Hebrok \& Boks, 2017). This typically involves media and/or online campaigns, which are mainly used to present food literacy information (e.g., purchasing, cooking, storage advice; Manzocco, Alongi, Sillani, \& Nicoli, 2016).

Building on printed food waste recycling information they provided to all multi-residential households, Bernstad, La Cour Jansen, and Aspegren (2013) tested the impact of door-to-door visits to present oral information on the environmental benefits of recycling food waste, but found no significant differences in the weight of food waste recycled compared with households that were not visited. Schmidt (2016) discovered that strengthening food literacy by providing volunteer households partially customized (from information gathered in an initial survey) food waste reduction information resulted in an improvement of perceived prevention ability and self-reported food waste preventing behaviors.

In a study on reducing university cafeteria plate waste, Jagau and Vyrastekova (2017) used posters that included relevant food wasting information and solutions as a nudge-based behavioral intervention. Customers were willing to ask for less food for the same price and their intentions to not waste food appeared to be nudged by personal norms, manifest as feelings of guilt and shame. The authors further suggest presenting information on household food wasting behavior in parts of a city, including relative performance, and to evoke social pressures, especially guilt and shame, as an intervention to reduce household food wasting. This echoes the work of Comber and Thieme (2013) who suggest that raising food waste awareness results in self-reflection and re-evaluation, and may lead to feelings of shame that one's attitudes are not manifest as requisite behavior. However, they also advocate the importance of perceived behavioral control to unlock behavioral change and highlight the significance of "signal triggers" to remind individuals about performing desirable behaviors.

Other researchers, such as Russell et al. (2017), propose that people who feel negative emotions about food waste and who intend to throw out less actually report throwing out more food, and argue for a more positive approach 
to interventions. Furthermore, they contend that noncognitive drivers, such as emotion and habit, should be considered as part of intervention development.

\section{Study Objectives and Hypotheses}

We developed and pilot-tested a "Reduce Food Waste, Save Money" household food waste reduction intervention in London, Ontario, Canada, and measured its impact on total, avoidable, and unavoidable household food waste disposal in the garbage stream. The rationale for undertaking this study is that there has been little research on household food waste behavior in North America, and to our knowledge, no research that has directly measured the change in curbside food waste disposal in the garbage stream after an intervention.

The theoretical context underpinning this intervention is using the TPB to facilitate behavior change. Visschers et al. (2016) reported on the positive impact of perceived behavioral control on intention to not waste food and self-reported food wasting behaviors. Strengthening this determinant can potentially be accomplished by improving food literacy. Our approach was to provide households with information on how to better manage food planning, purchase, storage, preparation, and leftovers. Although this approach arguably provides households with the tools to reduce food waste, the competing daily behavioral interests that consume household time (e.g., getting the children to school, working a full-time job, etc.) mean that achieving a desired behavior requires something more. In Table 3, survey respondents overwhelmingly selected "reduce amount of money wasted" over reducing environmental and social impacts as the key motivator to reducing food waste, confirming the conclusion of Stancu et al. (2016) that reducing this behavior may be motivated by self-interest. We posit that except perhaps for the very wealthy, the management of household monetary resources is an ongoing and largely automatic activity. That is, within the context of available resources people generally automatically seek out the most cost-effective goods and services. We therefore focussed part of our intervention on priming the need to save money, using locally calculated average dollars and quantity of food waste thrown out annually, with reduced environmental and social impacts presented as collateral benefits. To summarize, our intervention was developed to encourage reducing the amount of money lost on food waste, while building up household confidence or perceived behavioral control by providing households with information to increase their food literacy and help them better manage their food.

The first objective of this study was to test this intervention in an RCT and measure its impact on the amount of household food waste placed in the 
garbage on a household's garbage collection day. Researchers such as Visschers et al. (2016) and van der Werf and Gilliland (2018) recommended the direct collection, manual sorting, and weighing of food waste samples to measure food wasting behavior. A secondary objective was to develop and test a methodology to directly collect and sort household food waste from garbage samples.

Our study has one hypothesis:

Hypothesis 1 (H1): The change in total, avoidable, and unavoidable food waste set out will be significantly different between treatment and control households.

\section{Method}

\section{Procedure}

An intervention was pilot-tested on single-family households recruited as part of a household food waste survey, whose purpose was to better understand self-reported food waste disposal and possible behavioral determinants. Employing an RCT that included both treatment $(n=54)$ and control $(n=$ 58) households, the impact of this intervention was measured by comparing the weight of total, avoidable, and unavoidable food waste in pre- and postintervention curbside garbage samples.

Research was undertaken on single-family households in London, Ontario, Canada (City) (population 390,000). The City has a six-business day, sixzone garbage and recyclables curbside waste collection system for singlefamily households. Waste collection, disposal, and diversion are undertaken by a combination of municipal and contracted private sector forces. There is currently no curbside program to separately remove source-separated food wastes, although approximately 60,000 backyard composters have been distributed throughout the City in the last 25 years (J. Stanford, personal communication, May 15, 2017).

Household recruitment and selection. In addition to household recruitment, the survey provided data that supported this study. Using TPB as a conceptual framework, we developed a survey with 71 items, including questions from previously validated and well-used household/consumer food waste surveys primarily from Visschers et al. (2016), and also from Stancu et al. (2016) and WRAP (2007). The survey was administered online using Qualtrics survey software. The survey methodology is fully described (van der Werf et al., 2019). The mean and standard deviation were calculated for 
self-reported food wasting frequency and portions, by food type and by the total amount of food. Response scores per psychological construct were summed into a single index. For instance, the responses to the four questions on intention to avoid food waste were summed into a single intention index. Cronbach's alpha was used to measure the internal reliability of the scales that were used to assess the psychological constructs of intention, attitudes, subjective norms, perceived behavioral control, personal norms, good provider identity, and household planning habits. If the internal reliability was greater than .6 (i.e., reasonable, moderate), the mean was calculated and used in subsequent analyses (Taber, 2018). The foregoing is included in the Online Appendix (Table A.1).

A total of $N=1,263$ single-family households completed surveys, from which 418 single-family households volunteered for further study. Due to resource limitations, it was not possible to include all volunteer households in this study. The key dependent variables of this study were total and especially avoidable food waste in household garbage set out on their collection day. Unavoidable food waste was also used as a dependent variable. Sample size calculations were used to determine the required number of single-family volunteer households into treatment and control groups.

Sample size calculation and initial food waste sampling methodology. To assist with sample size calculations, data were used from a food waste quantity and composition pilot-study undertaken in London, Ontario in June 2016. A bespoke methodology was developed that used the methods described in (Stewardship Ontario, 2014; Waste Diversion Ontario, 2015) as a starting point, but, expanding it to include total, avoidable, and unavoidable food waste categories, as well as six food subtypes (i.e., bread baked goods, meat and fish, dairy, fruit and vegetables, dried food, and other food). These data were also used to calculate annual per household food waste disposal and the monetary value of that food waste, both of which were used in the intervention.

The methodology included the collection of curbside garbage samples from 100 representative households and manually sorting and weighing avoidable food waste. A post-intervention $20 \%$ reduction in treatment household avoidable food waste disposal, in the garbage stream, was considered practically meaningful. These households disposed a mean of $3.0 \mathrm{~kg} / \mathrm{collec}-$ tion of avoidable food waste ( $S D=1.1 \mathrm{~kg} /$ week). The foregoing inputs were used to calculate the sample size (Altman \& Gardner, 2000) required to detect a meaningful difference of $0.6 \mathrm{~kg}$ (i.e., $20 \%$ ) of avoidable food waste between the groups, assuming an alpha of .05. It was estimated that $n=53$ households were required for each group (i.e., treatment and control households). Thus, 
a minimum of 106 households were required to meet sample size calculation requirements.

As we wanted to assess the impact of the intervention on food waste set out (i.e., in the garbage stream), only households from which both pre- and postintervention garbage samples were collected could be used. There are two logistical challenges that can impede garbage sample collection and potentially hinder achieving the minimum sample size. From past study team experience, a minimum of $10 \%$ of households do not set out garbage on any given collection day. Second, even though the study team worked closely with the City of London to facilitate garbage sample collection, it was estimated that up to $10 \%$ of samples would inadvertently be collected by City waste collection vehicles prior to the arrival of the study team. Thus, to account for this estimated attrition, a $20 \%$ buffer of additional households was added to both preand post-intervention sampling rounds, resulting in a starting minimum of $n=$ 153 households (i.e., 106 households*1.2 = 132 households*1.2 $=153$ households), which was further rounded up to 160 households.

Selection of treatment and control households. The $n=418$ volunteer household locations were mapped and delineated by the City's six waste collection zones (i.e., collection in these zones occurs on consecutive weekdays). A total of 160 households were selected, consisting of 20 to 33 households per waste collection zone (as household volunteers per waste collection zone varied). Selecting sample households across all waste collection zones (i.e., urban and suburban) ensured the sample households represented the full range of socioeconomic status levels in the city. A focus was also on identifying clusters of households (i.e., households in reasonably close proximity to each other), in each waste collection zone, to facilitate rapid garbage/ food waste sample collection. The selection of these clusters was completed "blind" of the results of the survey.

During the pre-intervention sampling round, 21 household samples were missed for the anticipated reasons described above, leaving 139 households. From these remaining households, 10 to 12 treatment households were randomly selected, per waste collection zone, resulting in 66 treatment households. The remaining 73 volunteer households were used as controls and were distributed eight to 18 households per waste collection zone. Furthermore, a twin-block facing analysis was undertaken to ensure that households in close proximity (i.e., on the same block) were either all treatment or control (to minimize the chance that a participant in the treatment group might share intervention info with a neighbor participating in the control group). On that basis, three adjustments were made where a household was converted from treatment to control or vice versa. During the 
post-intervention sampling round, 27 household samples were missed for the anticipated reasons noted above, leaving a final sample of $n=54$ treatment households and $n=58$ control households, which were considered in data analysis.

Intervention development. An intervention called "Reduce Food Waste, Save Money" was developed to encourage reducing the amount of money wasted on food waste and strengthening perceived behavioral control, by providing food literacy messaging. This was accomplished by providing households in London, Ontario locally derived information on the quantity and average household value of food wasted, as well as information on environmental and social impacts of food wasting. The messaging focused on tips on how to do the following: improve food planning; efficiently purchase, store, and prepare food; and use leftovers, to ultimately reduce the amount of food that becomes waste. The intervention package used a commercially available 4-L container, designed to extend produce life, as an "envelope." The package included a "Reduce Food Waste, Save Money" postcard (Figure 2) affixed on the top of this container, along with a fridge magnet version of the postcard, and food waste reduction tools including an explanatory letter, freezer stickers, and a grocery list pad inside the container. All messaging included directions on how to access a purpose-built www.foodwaste.ca website, which provided additional details on the various food waste reduction tips provided on the postcard and fridge magnet.

The intervention package was delivered to treatment households on 2 October, 2017. Over the following 2 weeks, five email messages were sent to treatment households to reinforce that reducing the amount of food that became waste could save households money, to reiterate food waste reduction tips presented in the package, and to encourage visits to the website (see Online Appendix).

Collection and sorting of household food waste from garbage samples. A bespoke methodology to collect garbage and sort for food waste is described in the "Sample size calculation and initial food waste sampling methodology" section and this was logistically expanded to facilitate individual household food waste collection and analysis (i.e., rather than group collection and analysis). Selected households were mapped using geographic information system software to create efficient routes for collection of daily samples. Preintervention garbage samples were collected once from each of the City's six waste collection zones between 18 and 25 September 2017. Post-intervention garbage samples were similarly collected between 18 and 25 October 2017. The samples were collected on a household's normal garbage collection day and what was set out was collected by two sampling crews. Households were 


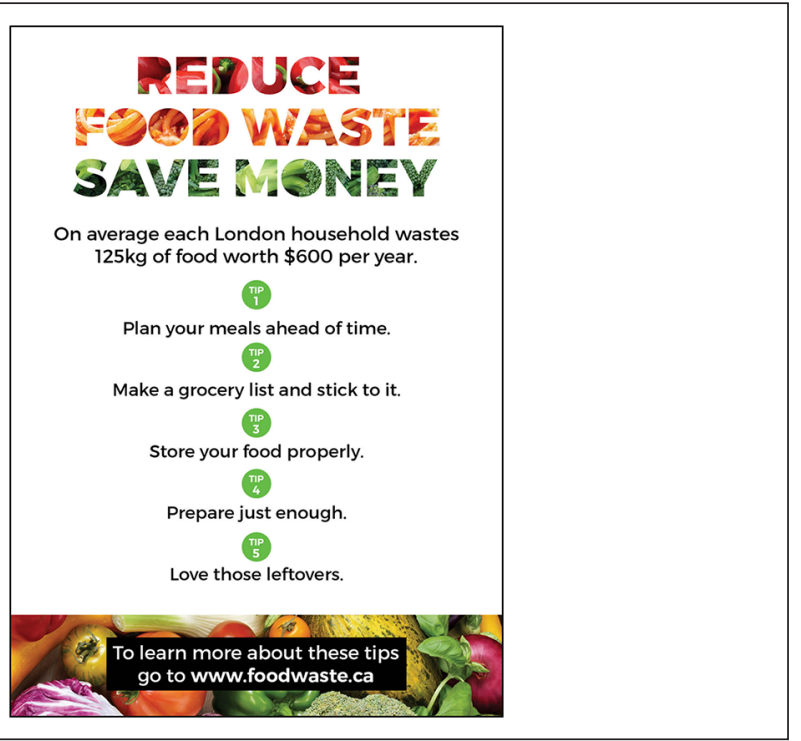

Figure 2. Postcard/fridge magnet included in intervention package.

not alerted to the specific day of the collection of these samples. Sample (i.e., bags of garbage) collection started at 7:00 a.m. in the morning and concluded by 8:30 a.m. each day. Samples were labeled, per household address, so that they could be identified after unloading. The number of recycling containers set out at the curb, by household, was also counted.

Household garbage samples were taken to an indoor sorting location. Each household garbage sample was individually weighed (using KPS60SS scale; $60 \mathrm{~kg}$ capacity, sensitive to $0.02 \mathrm{~kg}$ ) and then manually sorted into six avoidable and unavoidable food waste categories: bread and baked goods, meat and fish, dairy, fruit and vegetables, dried food, and other food. Each category of food waste was weighed (using A\&D SK-5001WP scale; 5,000 g capacity, sensitive to $1 \mathrm{~g}$ ). Weight data were expressed on a weekly basis for household garbage samples ( $\mathrm{kg} /$ week) and food waste categories (g/week).

Statistical analysis. Data were analyzed for the final treatment $(n=54)$ and control ( $n=58$ ) households, only if both the pre- and post-intervention garbage samples were collected. Independent variables including survey-related questions on food waste reduction motivators, sociodemographic factors (i.e., housing tenure, number of people in a household, number of children in a household, household income), pro-environmental behavior (i.e., backyard 
composter usage, recycling container set out), quantity of garbage set out, and TPB psychological constructs (Figure 1) were utilized in data analysis of treatment and control households.

Data were analyzed using IBM SPSS Statistics version 25 (Armonk, New York). Categorical variables were summarized as percentages, and continuous variables were presented as mean \pm standard deviation, as well as medians and percentages where appropriate. Independent samples $t$-tests were used to assess the mean difference in total, avoidable, and unavoidable pre- and postintervention food waste (i.e., dependent variables) between the treatment and control households. A $2 \times 2$ mixed-design analysis of variance (ANOVA) was used to compare mean differences in total, avoidable, and unavoidable food waste for the within-subjects factor (i.e., pre/post) and the between-subjects factor (i.e., treatment/control). The Wilcoxon signed-rank test was used to assess nonparametric related samples, and specifically to determine if there were statistically significant differences between food waste reduction motivators.

As the focus of the intervention was on avoidable food waste, correlation and regression analysis were undertaken on this dependent variable. The Spearman rank correlation coefficient was used to assess the bivariate strength and direction of the association between the amount of avoidable food wasted (i.e., focus of intervention), sociodemographic factors, and waste management factors (i.e., garbage set out, recycling set out, backyard composter usage). Correlation coefficients were interpreted as follows: $\geq .75=$ very good to excellent; .50 to $.75=$ moderate to good; 0.25 to $0.49=$ fair; and $\leq .25=$ little to no correlation (Colton, 1974). Multiple linear regression models were developed to assess the relative effects of various predictors on pre- and postintervention curbside avoidable food wasting behavior wasted. A two-sided $p$-value $\leq .05$ was considered statistically significant. Furthermore, we ran statistical interaction terms between treatment (yes/no) and the TPB variables. Specifically, statistical interaction terms were computed between treatment (yes/no) and the psychological construct/TPB variables. We also included treatment as a predictor variable in our models and ensured that multicollinearity was not problematic.

\section{Participants}

The sociodemographic profile of the participant treatment and control households is presented in Table 1. Treatment households tended to be slightly larger with more children, have higher incomes, and a higher rate of home ownership than control households; however, these differences were not statistically significant. The number of people and 
Table I. Sociodemographic Profile of Treatment $(n=54)$ and Control $(n=58)$ Households.

\begin{tabular}{lrccrc}
\hline $\begin{array}{l}\text { No. of people } \\
\text { in a household }\end{array}$ & $\begin{array}{c}\text { Treatment } \\
(\%)\end{array}$ & $\begin{array}{c}\text { Control } \\
(\%)\end{array}$ & $\begin{array}{c}\text { Household income } \\
(\text { US } \$)\end{array}$ & $\begin{array}{c}\text { Treatment } \\
(\%)\end{array}$ & $\begin{array}{c}\text { Control } \\
(\%)\end{array}$ \\
\hline 1 & 7.5 & 10.3 & $<40,000$ & 17.0 & 20.7 \\
2 & 30.2 & 32.8 & $40,000-60,000$ & 9.4 & 15.5 \\
3 & 18.9 & 20.7 & $60,000-80,000$ & 18.9 & 15.5 \\
4 & 20.8 & 24.1 & $80,000-100,000$ & 24.5 & 13.8 \\
5 & 20.8 & 6.9 & $>100,000$ & 30.2 & 34.5 \\
$6+$ & 1.9 & 5.2 & & & \\
\hline
\end{tabular}

No. of children in a household

Housing tenure

\begin{tabular}{lrrlrr}
\hline 0 & 50.0 & 56.1 & Live rent free & 0.0 & 5.2 \\
1 & 16.7 & 21.1 & Pay rent & 13.2 & 12.1 \\
2 & 16.7 & 14.0 & Pay mortgage & 66.0 & 60.3 \\
3 & 16.7 & 3.5 & Own home outright & 20.8 & 20.7 \\
4 & 0.0 & 5.3 & Other & 0.0 & 1.7 \\
$5+$ & 0.0 & 0.0 & & & \\
\hline
\end{tabular}

income in both treatment and control households were slightly higher compared with the city average (Statistics Canada, 2016), which was to be expected as our analysis focused on households in single-family dwellings, to the exclusion of households in apartments and other multiunit dwelling types.

\section{Results}

\section{Food Waste Set Out}

The average amount of garbage set out, for the post-intervention sample compared with the pre-intervention sample, decreased by $1.2 \mathrm{~kg} /$ household/ week $(-12 \%)$ for treatment households and increased by $0.2 \mathrm{~kg} /$ household/ week $(+2 \%)$ for control households (Table 2). Similarly, total mean food waste (i.e., avoidable + unavoidable food waste) decreased by $1,044 \mathrm{~g} /$ household or $31 \%$ for treatment households and increased by $21 \mathrm{~g} /$ household or $1 \%$ for control households. Avoidable food waste decreased by a mean of $634 \mathrm{~g} /$ household or $30 \%$ for treatment households. The amount of all food types decreased by at least $15 \%$. For control households, avoidable food 


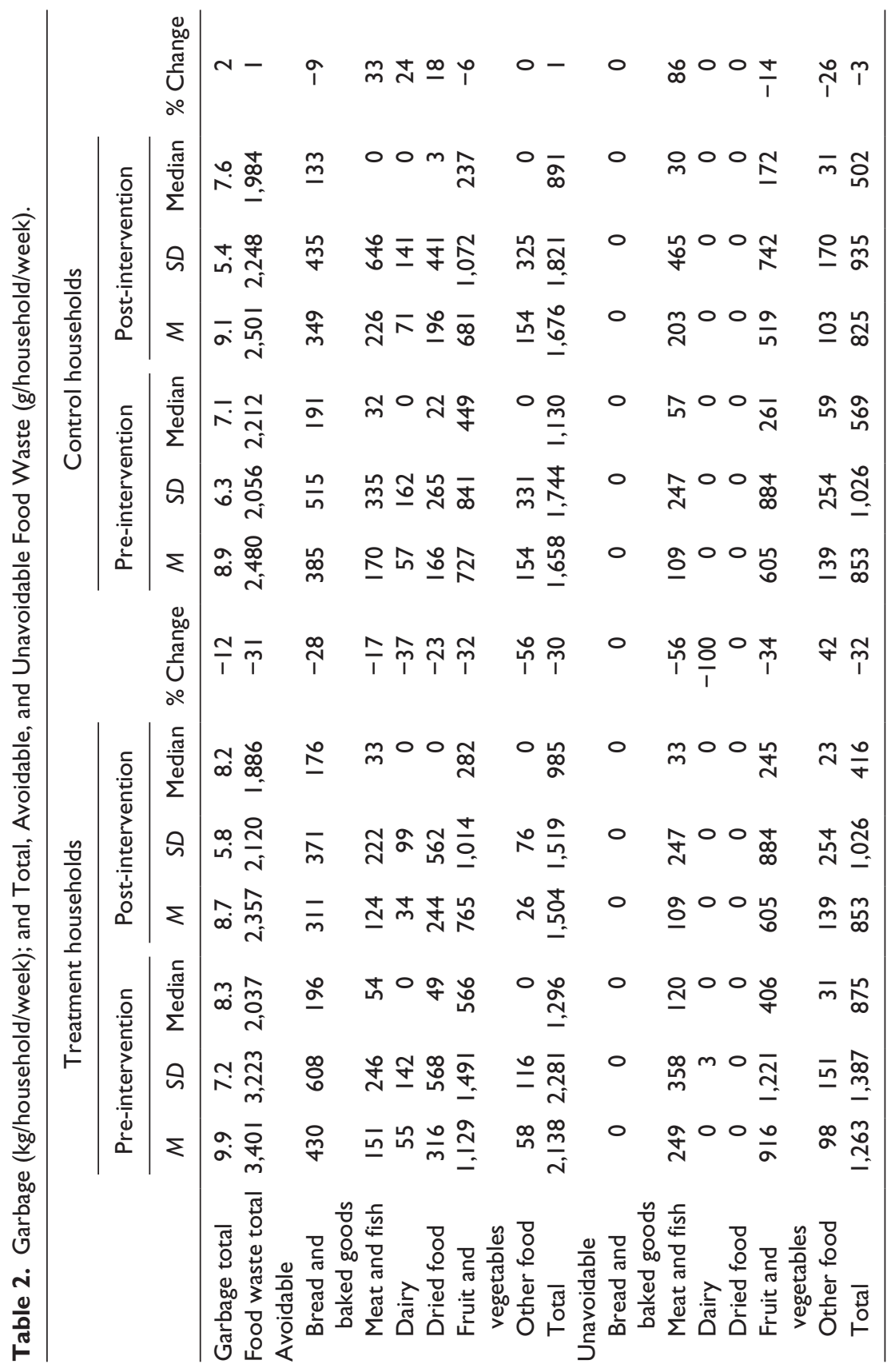


waste increased by a mean of $18 \mathrm{~g} /$ household/week or $1 \%$. Only bread and baked goods and fruits and vegetables decreased with some food types, such as meat and fish and dairy, increasing by more than $20 \%$. Fruit and vegetables, followed by bread and baked goods, were the top two ranked avoidable food waste types disposed for both intervention and control households.

There were statistically significant interactions between treatment group and total food waste $(F=5.735, p=.02)$, avoidable food waste $(F=3.881$, $p=.05)$ and unavoidable food waste $(F=4.034, p=.05)$, all favoring greater reductions in food waste in the treatment households.

\section{Overview of Food Wasting Behaviors}

It is important to understand not only if the intervention, which specifically targeted avoidable food waste, was successful, but also how it was successful. As noted, intervention development was informed by the most frequently selected food waste reduction motivator of "reduce amount of money wasted," as selected by overall household food waste survey respondents (Table 3). Treatment households also selected this motivator most frequently, although it was not significantly different from "reduce environmental impact." Control household motivator selection essentially mirrored the results of all survey respondents.

Correlations of sociodemographic factors, waste management factors, and psychological constructs with pre- and post-intervention avoidable food waste, by treatment and control households, were also measured to identify potential relationships (Table 4). The number of people in a household was significantly and positively correlated with total avoidable food waste for both post-intervention treatment and control households. The number of children in a household was significantly and positively correlated with total avoidable food waste for pre- and post-intervention control households only. Furthermore, as would be expected, the amount of pre-intervention and postintervention avoidable food waste was significantly and positively correlated with the amount of garbage set out for both treatment and control households. Backyard composter usage was significantly and negatively correlated with the amount of avoidable food waste set out for pre- and post-intervention treatment households and pre-intervention control households.

Psychological constructs, as related to food wasting behaviors, were measured as part of the household food waste survey. Intention and personal attitudes were negatively and significantly correlated, whereas food safety attitudes and the good provider identity were positively significantly correlated with post-intervention treatment household avoidable food waste. Perceived behavioral control was negatively and significantly correlated for 
Table 3. Ranking of Food Waste Reduction Motivators.

\begin{tabular}{|c|c|c|c|c|c|c|}
\hline \multirow[b]{2}{*}{ Motivator } & \multicolumn{2}{|c|}{ Overall } & \multicolumn{2}{|c|}{ Treatment } & \multicolumn{2}{|c|}{ Control } \\
\hline & $n$ & $\%$ & $n$ & $\%$ & $n$ & $\%$ \\
\hline Reduce amount of money wasted & 723 & $58.9^{a}$ & 27 & $50.0^{\mathrm{a}}$ & 33 & $56.8^{\mathrm{a}}$ \\
\hline $\begin{array}{l}\text { Reduce environmental impact } \\
\text { (climate change) }\end{array}$ & 294 & $23.9^{b}$ & 19 & $35.2^{\mathrm{a}, \mathrm{b}}$ & 14 & $24.1^{b}$ \\
\hline Reduce social impact (e.g., hunger) & 211 & $17.2^{\mathrm{c}}$ & 8 & $14.8^{\mathrm{c}}$ & 10 & $17.2^{\mathrm{c}}$ \\
\hline Total & 1,228 & 100 & 54 & 100 & 58 & 100 \\
\hline
\end{tabular}

Note. Values in columns with different superscripts are significantly different $(p<.00 \mathrm{I})$.

post-intervention avoidable food waste from treatment households and for both pre- and post-intervention avoidable food waste set out for control households. Personal norms were negatively and significantly correlated with pre- and post-intervention avoidable food waste for control households only. The good provider identity was positively and significantly correlated with pre- and post-intervention treatment household avoidable food waste, and positively and significantly correlated with pre-intervention control household avoidable food waste. There were no significant correlations of household income and financial attitudes with avoidable food waste for both treatment and control households.

Multiple linear regression models were developed for treatment and control pre- and post-intervention avoidable food waste (Table 5). Each of the models had a high fit $\left(R^{2}=.52-.59\right)$ and showed that garbage set out had a consistent positive and significant impact on the amount of avoidable food waste. For treatment households, personal norms, the good provider identity, and household planning habits had positive and significant impacts, while financial attitudes had a negative and significant impact on the amount of pre-intervention avoidable food waste. However, only the number of people in the household, garbage set out, and personal attitudes had a positive and significant impact on post-intervention avoidable food waste. We ran statistical interaction terms between treatment (yes/no) and the psychological construct (i.e., TPB) variables, and no interaction terms were statistically significant.

The pre- and post-intervention models were similar for control households, with housing tenure (i.e., in particular home ownership) having a significant negative impact and garbage set out a positive and significant impact on avoidable food waste. Perceived behavioral control had a negative and significant impact on avoidable food waste for the pre-intervention sample only. 


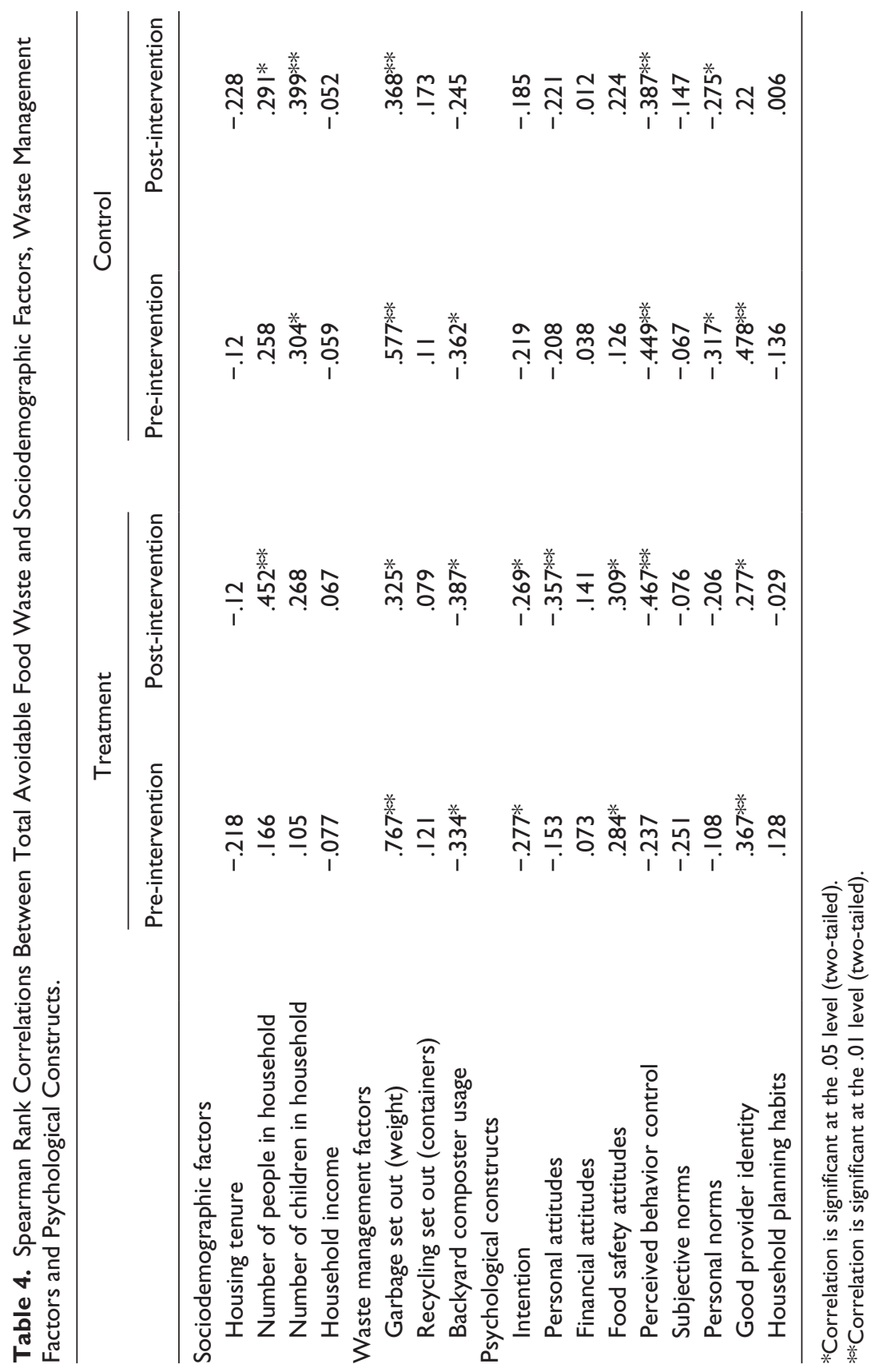


Table 5. Linear Regression Analysis on Avoidable Food Waste.

\begin{tabular}{|c|c|c|c|}
\hline & $B$ & $S E$ & $\beta$ \\
\hline \multicolumn{4}{|l|}{ Treatment households } \\
\hline \multicolumn{4}{|l|}{ Pre-intervention } \\
\hline Constant & $-3,572.30$ & $2,853.64$ & \\
\hline Recycling set out & $-8|8.05|$ & 418.103 & -.221 \\
\hline Garbage set out & 232.822 & 38.182 & $.745 * * *$ \\
\hline Financial attitudes & -274.926 & 89.241 & $-.413^{* *}$ \\
\hline Personal norms & 188.435 & 87.546 & $.259 *$ \\
\hline Good provider identity & 185.124 & 55.054 & $.0426 * *$ \\
\hline Household planning habits & $17 \mid .468$ & 71.904 & $.278^{*}$ \\
\hline Model statistics & \multicolumn{3}{|c|}{$R^{2}=.59, F(6,34)=10.573, p<.001$} \\
\hline \multicolumn{4}{|l|}{ Post-intervention } \\
\hline Constant & $3,580.27$ & $1,443.01$ & \\
\hline $\begin{array}{l}\text { Number of people in } \\
\text { household }\end{array}$ & 340.297 & 164.875 & $.222^{*}$ \\
\hline Garbage set out & 121.092 & 27.175 & $.489 * * *$ \\
\hline Personal attitudes & -250.772 & 70.197 & $-.38 I * *$ \\
\hline Model statistics & \multicolumn{3}{|c|}{$R^{2}=.58, F(3,37)=19.036, p<.001$} \\
\hline \multicolumn{4}{|l|}{ Control households } \\
\hline \multicolumn{4}{|l|}{ Pre-intervention } \\
\hline Constant & $5,520.77$ & $1,673.45$ & \\
\hline Housing tenure & -679.461 & 321.721 & $-.242 *$ \\
\hline Garbage set out & 168.384 & 39.294 & $.51 \mathrm{I} * * *$ \\
\hline Perceived behavioral control & -124.698 & 38.962 & $-.384 * *$ \\
\hline Model statistics & \multicolumn{3}{|c|}{$R^{2}=.52, F(3,34)=|4.48|, p<.00 \mid$} \\
\hline \multicolumn{4}{|l|}{ Post-intervention } \\
\hline Constant & $2,046.96$ & $1,225.08$ & \\
\hline Housing tenure & -881.196 & 330.356 & $-.312^{*}$ \\
\hline Garbage set out & 151.559 & 41.916 & $.481 * *$ \\
\hline Recycling set out & 477.42 & 248.775 & .252 \\
\hline Model statistics & \multicolumn{3}{|c|}{$R^{2}=.52, F(3,34)=|4.08|, p<.00 \mid$} \\
\hline
\end{tabular}

Note. This table consists of four linear regression models, that is, pre- and post-intervention models for both treatment and control households.

$*_{p}<0.05,{ }^{* *} p<0.01$, *** $p<0.001$.

As part of the household food waste survey, households were asked why they wasted different food types. For treatment households, buying too much was the most common reason for disposing bread and baked goods, dairy, fruit and vegetables, and other food, whereas for meat and fish it was because 


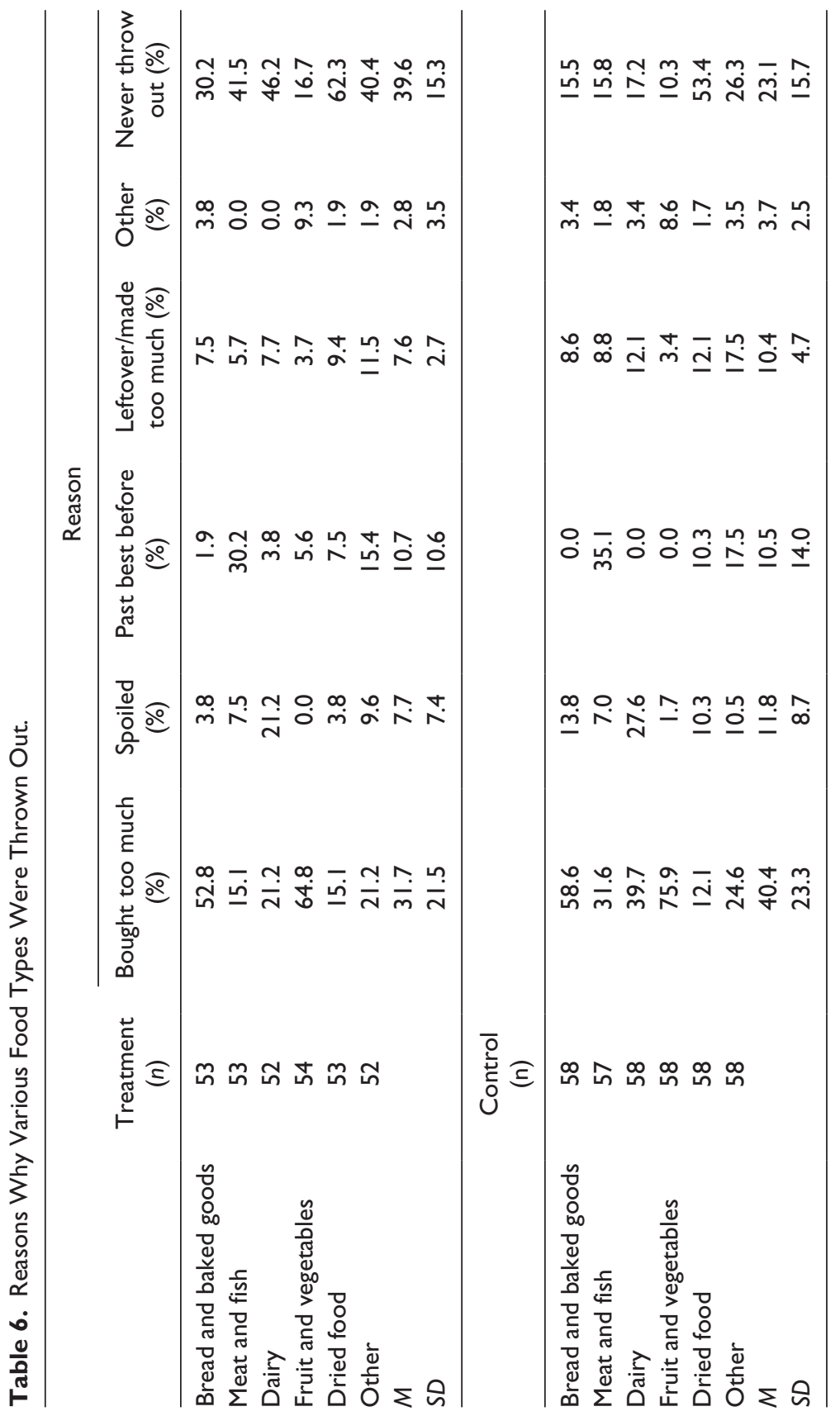


it was past its best before date (Table 6). The mean was calculated across all food types, and showed that the most common reasons for throwing out food were buying too much, food spoilage, and food that is past its best before date. The amount of food never thrown out ranged between $16.7 \%$ for fruit and vegetables to $62.3 \%$ for dried food. The reasons why food was disposed of were similar, but more pronounced, for control households. However, the percentage of these households reporting that they "never throw out" was less for all food types when compared with treatment households.

\section{Discussion}

In one of the first studies of its kind, a household food waste reduction intervention, which was theoretically informed by the TPB, was successfully tested using an RCT design (i.e., treatment and control). In short, this intervention attempted to encourage money saving behaviors by providing households with locally calculated information on quantities and monetary impacts of their food waste, along with food literacy information, designed to strengthen perceived behavioral control, by providing behavioral tips to reduce the behaviors (e.g., buying too much, food storage) that can lead to food waste generation. The foregoing allowed us to meet the primary objective of this study. Furthermore, by using a bespoke methodology, household food wasting behavior was directly and successfully measured. This included the collection of pre- and post-intervention curbside garbage samples, and measuring total, avoidable, and unavoidable food waste. This allowed us to meet the secondary objective of this study.

Pre- and post-intervention differences in total $(p=.02)$, avoidable ( $p=$ $.05)$, and unavoidable $(p=.05)$ food waste were significantly different between treatment and control households, meaning that our hypothesis (H1) was confirmed.

\section{Possible Reasons for Decreased Food Waste Set Out by Treatment Households}

There are several factors that could explain the differences in food waste disposed in the garbage stream between treatment and control household food waste reduction.

Quantity of pre-intervention treatment household food waste. Although randomly selected, treatment households had considerably higher mean food waste set out $(3,401 \mathrm{~g} /$ week, $S D=3,233)$ in pre-intervention samples as 
compared with control households $(2,480 \mathrm{~g} /$ week, $S D=2,056)$. Post-intervention treatment household mean food waste set out $(2,357 \mathrm{~g} / \mathrm{week}, S D=$ $2,120)$ was similar to control households $(2,501 \mathrm{~g} /$ week, $S D=2,248)$. Treatment households tended to have more people and children than control households. That is, treatment households generated more pre-intervention food waste at least in part due to their size, meaning that they have greater opportunity to respond to a food waste reduction intervention and intimating a possible food waste quantity response threshold. This response is in part borne out by the positive correlation $(r=.45, p=.01)$ between post-intervention treatment household food waste disposed and number of people in a household, and the emergence of number of people in a household as a positive and significant predictor in post-intervention regression analysis. Furthermore, the response of treatment households to the intervention appeared to be comprehensive rather than coincidental, as all avoidable food waste types decreased by $17 \%$ to $56 \%$, but generally increased or resulted in small decreases for control households. There were similar but less pronounced results for unavoidable food waste. The obverse of the preceding is that quantities of food waste set out by control households were relatively stable.

Impact of food waste reduction motivators. Both treatment and control households identified "reducing the amount of money wasted" as the key motivator that would spur them to reduce food waste. Furthermore, both treatment and control households reported that the over purchase of food was the most consistent reason why food was thrown out, suggesting a recognition that this is a money wasting behavior. In the intervention, this idea was molded after Russell et al. (2017), as the positive message of reducing food waste to save money. However, save for the pre-intervention regression analysis of treatment households, where financial attitudes related to wasting food were significantly and negatively associated with food waste set out, monetary matters were not reflected in any correlations and regression analyses between household income or financial attitudes and avoidable food waste set out. This suggests a possible discontinuity between this motivator, and financial attitudes and household income. Importantly, it did not appear to have any real bearing on post-intervention treatment household avoidable food waste set out, although any change in financial attitudes as a result of the intervention was not measured.

Mindful that our intervention was not based on preventing environmental impacts, for treatment households reducing monetary and environmental impacts motivators were not significantly different, suggesting that perhaps pro-environmental behaviors contribute to the amount of food waste set out. 
Sintov, Geislar, and White (2017) suggested one pro-environmental behavior such as placing food waste in a composting bin could spill over into other proenvironmental behaviors such as food waste prevention behaviors. Although they reported spillover effects to residential energy and water waste prevention because of compost bin usage, none was noted for food waste prevention. We examined recycling and backyard composting pro-environmental behaviors; there were no correlations between recycling set out (i.e., that would have occurred on the same day as collection of food waste samples) and avoidable food waste set out. However, backyard composter usage, as measured during the household food waste survey, was fairly and negatively correlated with avoidable food waste set out. Furthermore, the anti-environmental behavior of higher quantity garbage set out was consistently and fairly to excellently correlated with avoidable food waste in the garbage. Indeed, garbage set out, as depicted in regression analyses, was a consistent and arguably the key predictor of avoidable food waste set out for both treatment and control households.

Psychological constructs. There was a change, from not significant to significant, in the treatment household TPB psychological constructs of perceived behavioral control and personal attitudes correlations, between the pre- and post-intervention avoidable food waste set out, suggesting possible intervention response triggers. This is tempered somewhat because for control households perceived behavioral control was significantly correlated with both pre- and post-intervention food waste set out, and this also carried through to linear regression analysis for pre-intervention food waste samples. This does speak to the relative importance of perceived behavioral control's relationship (i.e., as compared with intention) and possible role as a predictor of food waste. The change in perceived behavioral control as a result of the intervention was not measured.

There was a considerable change in regression models between pre- and post-intervention treatment households. Personal norms, the good provider identity, and household planning habits were significantly related to more avoidable food wasting, whereas financial attitudes were significantly related to less food wasting for pre-intervention treatment households.

As expected, the good provider identity was positively correlated to avoidable food wasting in both treatment and control households, suggesting that it may be a useful determinant and possible intervention point. Household planning habits were inconsistently correlated with avoidable food waste set out. Interestingly, personal norms and household planning habits were positively related to pre-intervention but not post-intervention avoidable food waste in treatment households. 
For post-intervention treatment households, personal attitudes emerged as the most consistent determinant of avoidable food waste. Beyond that, food waste set out is predicted by the amount of garbage set out, as in pre-intervention households, and the number of people in the household.

From the TPB perspective, the intervention focussed on trying to strengthen perceived behavioral control, by enhancing household food literacy. Although there were generally fair correlations with avoidable food wasting behavior, it offered little to no predictive capacity, as evidenced in regression analyses and no statistically significant interaction terms. Any change in household perceived behavioral control, after intervention delivery, was not measured in this study.

\section{Comparison With Other Similar Studies}

Although there are a growing number of survey-based studies that investigated the determinants of food wasting behaviors and measures of selfreported household food wasting (Stancu et al., 2016; Stefan et al., 2013; Visschers et al., 2016), and a few studies that have directly measured actual household food waste (Bernstad et al., 2013; Bernstad, La Cour Jansen, \& Aspegren, 2012; Lebersorger \& Schneider, 2011; Parizeau et al., 2015; van der Werf, Seabrook, \& Gilliland, 2018; WRAP, 2013c), few researchers have directly measured food waste before and after a reduction intervention.

Parizeau et al. (2015) reported that the households they surveyed in Guelph, Ontario set out an average of $7.1 \mathrm{~kg} /$ household/week of garbage and $12.5 \mathrm{~kg} /$ household/week of organic waste (which consisted largely of food waste). This compares with 8.9 to $9.9 \mathrm{~kg} /$ household/week of pre-intervention garbage for London, Ontario households, of which 2.5 to $3.4 \mathrm{~kg} /$ household/ week was total food waste. This food waste range compares favorably with the estimated $2.6 \mathrm{~kg} /$ household/week of total food waste generated by southern Ontario households without access to a program to remove source-separated food wastes (van der Werf et al., 2018). As expected, this is higher than for households with such a program (i.e., diversion of mostly food waste to large-scale composting or anaerobic digestion facilities), which on average disposed $2.3 \mathrm{~kg} /$ household/week of food waste (van der Werf et al., 2018). This speaks well to the methodology developed and deployed to directly collect household food waste data.

WRAP launched the Love Food Hate Waste (LFHW) in 2007 and focuses on providing households with information about their food waste and how to reduce it. They used, among other methods, the direct measurement of household food waste, to extrapolate and develop broad jurisdictional food waste estimates (Quested et al., 2011; WRAP, 2009, 2013a, 2013c). They reported 
that food waste disposal declined by approximately 1.1 million tons, from 8.3 million tons to 7.2 million tons by 2010 , with at least some of that $13 \%$ decrease attributable to the LFHW program and some to poor economic conditions (Quested et al., 2013; Quested et al., 2011). Our 31\% decrease in food waste set out between pre-intervention and post-intervention treatment household food waste compares favorably but has unknown long-term sustainability.

\section{Future Research}

Although this intervention looks promising, further research is required to understand if the reduction of food waste set out is sustainable in the longterm, and if not, what would be required to sustain this behavior. This would require the collection of additional garbage samples.

Further research is also required to understand if and how treatment household psychological constructs were altered as part of this intervention. For instance, have household financial attitudes about wasting food and perceived behavioral control been strengthened? This could include a follow-up survey. It would also be interesting to repeat and compare this intervention in another community with a program to separately remove source-separated food wastes as well as other ones without such program.

\section{Limitations}

The key limitation of this study is that it measures only food waste found in the garbage stream. As such, this represents the minimum amount of food waste generated at the household and does not account for food poured down the drain, fed to pets, and put into a backyard composter. There is currently no existing objective methodology (i.e., one that does not involve households self-reporting their behavior) to gather these data.

\section{Conclusion}

A household food waste reduction intervention was developed and tested in London, Ontario, Canada, and resulted in a decrease of total (31\%), avoidable (30\%), and unavoidable (32\%) food waste. Furthermore, we were able to successfully develop and implement a bespoke methodology to directly collect food waste samples, as recommended by researchers such as Visschers et al. (2016), to measure the aforementioned impact of this intervention. Key determinants of household food waste reduction efforts appeared to include personal attitudes, perceived behavioral control, the number of people in a 
household, and the amount of garbage set out. The sustainability and repeatability of this intervention should be investigated further.

\section{Acknowledgments}

The authors acknowledge Mr. Jay Stanford, Director, Environment, Fleet \& Solid Waste, City of London, Ontario, Canada for assistance in distributing this survey and supplying the table of contents graphic; and Mr. Martin Zivack and Ms. Angela Piaskoski for research assistance.

\section{Declaration of Conflicting Interests}

The author(s) declared no potential conflicts of interest with respect to the research, authorship, and/or publication of this article.

\section{Funding}

The author(s) disclosed receipt of the following financial support for the research, authorship, and/or publication of this article: This work was funded by Social Sciences and Humanities Research Council of Canada (Grant \#430-2017-01113).

\section{ORCID iD}

Paul van der Werf (iD) https://orcid.org/0000-0002-4389-832X

\section{Supplemental Material}

Supplemental material for this article is available online.

\section{References}

Abeliotis, K. (2014). Attitudes and behaviour of Greek households regarding food waste prevention. Waste Management \& Research, 32, 237-240. doi:10.1177/07 $34242 X 14521681$

Agriculture and Agri-Food Canada. (2015). An overview of the Canadian agriculture and agri-food system. Retrieved from http://www.agr.gc.ca/eng/about-us/ publications/economic-publications/an-overview-of-the-canadian-agricultureand-agri-food-system-2015/?id $=1428439111783$

Ajzen, I. (1991). The theory of planned behavior. Organizational Behavior and Human Decision Processes, 50, 179-211.

Altman, D. G., \& Gardner, M. J. (2000). Statistics with confidence: Confidence intervals and statistical guidelines (2nd ed.). London, England: BMJ Books.

Aschemann-Witzel, J., de Hooge, I., Amani, P., Bech-Larsen, T., \& Oostindjer, M. (2015). Consumer-related food waste: Causes and potential for action. Sustainability, 7, 6457-6477. doi:10.3390/su7066457

Baker, D., Fear, J., \& Denniss, R. (2009). What a waste: An analysis of household expenditure on food. Retrieved from http://www.tai.org.au/node/1580 
Beretta, C., Stoessel, F., Baier, U., \& Hellweg, S. (2013). Quantifying food losses and the potential for reduction in Switzerland. Waste Management, 33, 764-773. doi:10.1016/j.wasman.2012.11.007

Bernstad, A. (2014). Household food waste separation behavior and the importance of convenience. Waste Management, 34, 1317-1323. doi:10.1016/j.wasman.2014.03.013

Bernstad, A., La Cour Jansen, J., \& Aspegren, A. (2013). Door-stepping as a strategy for improved food waste recycling behaviour: Evaluation of a full-scale experiment. Resources, Conservation and Recycling, 73, 94-103. doi:10.1016/j.resconrec.2012.12.012

Bernstad, A., La Cour Jansen, J., \& Aspegren, H. (2012). Local strategies for efficient management of solid household waste: The full-scale Augustenborg experiment. Waste Management \& Research, 30, 200-212. doi:10.1177/0734242X11410113

BIO Intelligence Service. (2011). Guidelines on preparation of food waste prevention programmes (Framework Contract ENV.G.4/FRA/2008/0112). Retrieved from http://ec.europa.eu/environment/waste/prevention/pdf/prevention_guidelines.pdf

Bolton, L. E. (2012). When less is more: Consumer aversion to unused utility. Journal of Consumer Psychology, 22, 369-383. doi:10.1016/j.jcps.2011.09.002

Buzby, J., \& Hyman, J. (2012). Total and per capita value of food loss in the United States. Food Policy, 37, 561-570. doi:10.1016/j.foodpol.2012.06.002

Cappellini, B. (2009). The sacrifice of re-use: The travels of leftovers and family relations. Journal of Consumer Behaviour, 8, 365-375. doi:10.1002/cb.299

Cappellini, B., \& Parsons, E. (2012). Practising thrift at dinnertime: Mealtime leftovers, sacrifice and family membership. The Sociological Review, 60(Suppl. 2), 121-134. doi:10.1111/1467-954X.12041

Colton, T. (1974). Regression and correlation. Boston, MA: Little, Brown \& Company.

Comber, R., \& Thieme, A. (2013). Designing beyond habit: Opening space for improved recycling and food waste behaviors through processes of persuasion, social influence and aversive affect. Personal and Ubiquitous Computing, 17, 1197-1210.

Cuéllar, A. D., \& Webber, M. E. (2010). Wasted food, wasted energy: The embedded energy in food waste in the United States. Environmental Science \& Technology, 44, 6464-6469. doi:10.1021/es100310d

Evans, D. (2011). Blaming the consumer-once again: The social and material contexts of everyday food waste practices in some English households. Critical Public Health, 21, 429-440.

Evans, D. (2012). Beyond the throwaway society: Ordinary domestic practice and a sociological approach to household food waste. Sociology, 46, 41-56. doi: $10.1177 / 0038038511416150$

Food and Agriculture Organization of the United Nations, The International Fund for Agricultural Development, \& World Food Programme. (2015). The state of food insecurity in the world. Retrieved from http://www.fao.org/3/a-i4646e.pdf

Fusions. (2014). Drivers of current food waste generation, threats of future increase and opportunities for reduction. Available from http://www.eu-fusions.org 
Ganglbauer, E., Fitzpatrick, G., \& Comber, R. (2013). Negotiating food waste: Using a practice lens to inform design. ACM Transactions on Computer-Human Interaction, 20(2), Article 11.

Göbel, C., Langen, N., Blumenthal, A., Teitscheid, P., \& Ritter, G. (2015). Cutting food waste through cooperation along the food supply chain. Sustainability, 7, 1429-1445. doi:10.3390/su7021429

Gollwitzer, P. M. (1999). Implementation intentions: Strong effects of simple plans. American Psychologist, 54, 493-503.

Graham-Rowe, E., Jessop, D. C., \& Sparks, P. (2014). Identifying motivations and barriers to minimising household food waste. Resources, Conservation and Recycling, 84, 15-23. doi:10.1016/j.resconrec.2013.12.005

Graham-Rowe, E., Jessop, D. C., \& Sparks, P. (2015). Predicting household food waste reduction using an extended theory of planned behaviour. Resources, Conservation and Recycling, 101, 194-202. doi:10.1016/j.resconrec.2015.05.020

Gustavsson, J., Cederberg, C., Sonesson, U., Van Otterdijk, R., \& Meybeck, A. (2011). Global food losses and food waste: Extent, causes and prevention. Retrieved from http://www.fao.org/docrep/014/mb060e/mb060e.pdf

Halloran, A., Clement, J., Kornum, N., Bucatariu, C., \& Magid, J. (2014). Addressing food waste reduction in Denmark. Food Policy, 49(Pt. 1), 294-301. doi:10.1016/j. foodpol.2014.09.005

Hebrok, M., \& Boks, C. (2017). Household food waste: Drivers and potential intervention points for design-An extensive review. Journal of Cleaner Production, 151, 380-392. doi:10.1016/j.jclepro.2017.03.069

Hoj, S. B. (2012). Metrics and measurement methods for the monitoring and evaluation of household food waste prevention interventions. (Masters in Business), University of South Australia, Australia.

Jagau, H. L., \& Vyrastekova, J. (2017). Behavioral approach to food waste: An experiment. British Food Journal, 119, 882-894. doi:10.1108/BFJ-05-2016-0213

Jorissen, J., Priefer, C., \& Brautigam, K.-R. (2015). Food waste generation at household level: Results of a survey among employees of two European research centers in Italy and Germany. Sustainability, 7, 2695-2715. doi:10.3390/su7032695

Koivupuro, H.-K., Hartikainen, H., Silvennoinen, K., Katajajuuri, J.-M., \& Heikintalo, N. (2012). Influence of socio-demographical, behavioural and attitudinal factors on the amount of avoidable food waste generated in Finnish households. International Journal of Consumer Studies, 36, 183-191. doi:10.1111/j.14706431.2011.01080.x

Lebersorger, S., \& Schneider, F. (2011). Discussion on the methodology for determining food waste in household waste composition studies. Waste Management, 31, 1924-1933.

Lundqvist, J., de Fraiture, C., \& Molden, D. (2008). Saving water: From field to fork: Curbing losses and wastage in the food chain. Stockholm, Sweden: Stockholm International Water Institute.

Manzocco, L., Alongi, M., Sillani, S., \& Nicoli, M. C. (2016). Technological and consumer strategies to tackle food wasting. Food Engineering Reviews, 8, 457-467. doi:10.1007/s12393-016-9149-z 
Melbye, E. L., Onozaka, Y., \& Hansen, H. (2017). Throwing it all away: Exploring affluent consumers' attitudes toward wasting edible food. Journal of Food Products Marketing, 23, 416-429. doi:10.1080/10454446.2015.1048017

Neff, R. A. (2015). Wasted food: U.S. consumers' reported awareness, attitudes, and behaviors. PLoS ONE, 10(6), e0127881. doi:10.1371/journal.pone.0127881

Parfitt, J., Barthel, M., \& MacNaughton, S. (2010). Food waste within food supply chains: Quantification and potential for change to 2050. Philosophical Transactions of the Royal Society B: Biological Sciences, 365, 3065-3081. doi:10.1098/rstb.2010.0126

Parizeau, K., von Massow, M., \& Martin, R. (2015). Household-level dynamics of food waste production and related beliefs, attitudes, and behaviours in Guelph, Ontario. Waste Management, 35, 207-217. doi:10.1016/j.wasman.2014.09.019

Pearson, D., Minehan, M., \& Wakefield-Rann, R. (2013). Food waste in Australian households: Why does it occur. The Australasian-Pacific Journal of Regional Food Studies, 3, 118-132.

Porpino, G. (2016). Household food waste behavior: Avenues for future research. Journal of the Association for Consumer Research, 1, 41-51. doi:10.1086/684528

Principato, L., Secondi, L., \& Pratesi, C. A. (2015). Reducing food waste: An investigation on the behaviour of Italian youths. British Food Journal, 117, 731-748. doi:10.1108/BFJ-10-2013-0314

Quested, T. E., Marsh, E., Stunell, D., \& Parry, A. D. (2013). Spaghetti soup: The complex world of food waste behaviours. Resources, Conservation and Recycling, 79, 43-51. doi:10.1016/j.resconrec.2013.04.011

Quested, T. E., Parry, A. D., Easteal, S., \& Swannell, R. (2011). Food and drink waste from households in the UK. Nutrition Bulletin, 36, 460-467. doi:10.1111/j.14673010.2011.01924.x

Russell, S. V., Young, C. W., Unsworth, K. L., \& Robinson, C. (2017). Bringing habits and emotions into food waste behaviour. Resources, Conservation and Recycling, 125, 107-114.

Schanes, K., Dobernig, K., \& Gözet, B. (2018). Food waste matters-A systematic review of household food waste practices and their policy implications. Journal of Cleaner Production, 182, 978-991.

Schmidt, K. (2016). Explaining and promoting household food waste-prevention by an environmental psychological based intervention study. Resources, Conservation and Recycling, 111, 53-66. doi: http://dx.doi.org/10.1016/j.resconrec.2016.04.006

Secondi, L., Principato, L., \& Laureti, T. (2015). Household food waste behaviour in EU-27 countries: A multilevel analysis. Food Policy, 56, 25-40. doi:10.1016/j. foodpol.2015.07.007

Seebauer, S., Fleiß, J., \& Schweighart, M. (2017). A household is not a person: Consistency of pro-environmental behavior in adult couples and the accuracy of proxy-reports. Environment and Behavior, 49, 603-637.

Sintov, N., Geislar, S., \& White, L. V. (2017). Cognitive accessibility as a new factor in proenvironmental spillover: Results from a field study of household food waste management. Environment and Behavior, 51, 50-80. 
Stancu, V., Haugaard, P., \& Lahteenmaki, L. (2016). Determinants of consumer food waste behaviour: Two routes to food waste. Appetite, 96, 7-17. doi:10.1016/j. appet.2015.08.025

Statistics Canada. (2015). Food insecurity in Canada. Retrieved from http://www. statcan.gc.ca/pub/82-624-x/2015001/article/14138-eng.pdf

Statistics Canada. (2016). Census profile, 2016 census, London [Census metropolitan area], Ontario and Ontario [province]. Retrieved from http://www12.statcan. gc.ca/census-recensement/2016/dp-pd/prof/details/page.cfm?Lang=E\&Geo1=C MACA $\&$ Code $1=555 \&$ Geo $2=$ PR $\&$ Code $2=35 \&$ Data $=$ Count $\&$ SearchText $=$ londo $\mathrm{n} \&$ SearchType $=$ Begins $\&$ SearchPR $=01 \& \mathrm{~B} 1=\mathrm{All} \& \mathrm{TABID}=1$

Stefan, V., van Herpen, E., Tudoran, A. A., \& Lähteenmäki, L. (2013). Avoiding food waste by Romanian consumers: The importance of planning and shopping routines. Food Quality and Preference, 28, 375-381. doi:10.1016/j.foodqual.2012 .11 .001

Stewardship Ontario. (2014). Curbside single and multi-family waste composition studies.

Taber, K. S. (2018). The use of Cronbach's alpha when developing and reporting research instruments in science education. Research in Science Education, 48, 1273-1296. doi:10.1007/s11165-016-9602-2

Thyberg, K. L., \& Tonjes, D. J. (2016). Drivers of food waste and their implications for sustainable policy development. Resources, Conservation and Recycling, 106, 110-123. doi:10.1016/j.resconrec.2015.11.016

Thyberg, K. L., Tonjes, D. J., \& Gurevitch, J. (2015). Quantification of food waste disposal in the United States: A meta-analysis. Environmental Science \& Technology, 49, 13946-13953. doi:10.1021/acs.est.5b03880

Tucker, C., \& Farrelly, T. (2016). Household food waste: The implications of consumer choice in food from purchase to disposal. Local Environment, 21, 682-706.

van der Werf, P., \& Gilliland, J. A. (2017). A systematic review of food losses and food waste generation in developed countries. Proceedings of the Institution of Civil Engineers-Waste and Resource Management, 170, 66-77.

van der Werf, P., Seabrook, J. A., \& Gilliland, J. A. (2018). The quantity of food waste in the garbage stream of southern Ontario, Canada households. PLoS ONE, 13(6), e0198470.

van der Werf, P., Seabrook, J. A., \& Gilliland, J. A. (2019). Food for naught: Using the theory of planned behaviour to better understand household food wasting behaviour. The Canadian Geographer/Le Géographe Canadien, 63(2), 1-16. doi:10.1111/cag.12519

Van Garde, S. J., \& Woodburn, M. J. (1987). Food discard practices of householders. Journal of the American Dietetic Association, 87, 322-329.

Verghese, K., Lewis, H., Lockrey, S., \& Williams, H. (2015). Packaging's role in minimizing food loss and waste across the supply chain. Packaging Technology and Science, 28, 603-620.

Visschers, V., Wickli, N., \& Siegrist, M. (2016). Sorting out food waste behaviour: A survey on the motivators and barriers of self-reported amounts of food waste 
in households. Journal of Environmental Psychology, 45, 66-78. doi:10.1016/j. jenvp.2015.11.007

Waste Diversion Ontario. (2015). Terms of reference: Curbside and multi-residential waste composition studies. Retrieved from https://thecif.ca/wp-content /uploads/2016/09/wdo-curbside-multires-waste-composition-studies-finalapril2016.pdf

Watson, M., \& Meah, A. (2012). Food, waste and safety: Negotiating conflicting social anxieties into the practices of domestic provisioning food, waste and safety. The Sociological Review, 60(Suppl. 2), 102-120. doi:10.1111/1467-954X.12040

Weber, C. L., \& Matthews, H. S. (2008). Food-miles and the relative climate impacts of food choices in the United States. Environmental Science \& Technology, 42, 3508-3513. doi:10.1021/es702969f

Williams, H., Wikstrom, F., Otterbring, T., Lofgren, M., \& Gustafsson, A. (2012). Reasons for household food waste with special attention to packaging. Journal of Cleaner Production, 24, 141-148. doi:10.1016/j.jclepro.2011.11.044

Waste \& Resources Action Programme. (2007). Food behaviour consumer research: Quantitative phase. Retrieved from http://www.wrap.org.uk/sites/ files/wrap/Food\%20behaviour\%20consumer\%20research\%20quantitative $\% 20$ jun\%202007.pdf

Waste \& Resources Action Programme. (2009). Household food and drink waste in the UK. Retrieved from http://www.wrap.org.uk/sites/files/wrap/Household_ food_and_drink_waste_in_the_UK___report.pdf

Waste \& Resources Action Programme. (2011). Final report. Consumer insight: Date labels and storage guidance. Retrieved from http://www.wrap.org.uk/sites/files/ wrap/Technical\%20report\%20dates.pdf

Waste \& Resources Action Programme. (2013a). Annex report (v2): Methods used for household food and drink waste in the UK 2012. Retrieved from http://www. wrap.org.uk/sites/files/wrap/Methods\%20Annex\%20Report\%20v2.pdf

Waste \& Resources Action Programme. (2013b). Estimates of waste in the food and drink supply chain. Retrieved from http://www.wrap.org.uk/sites/files/ wrap/Estimates\%20of\%20waste $\% 20$ in $\% 20$ the $\% 20$ food $\% 20$ and $\% 20$ drink $\% 20$ supply\%20chain_0.pdf

Waste \& Resources Action Programme. (2013c). Household food and drink waste in the United Kingdom 2012. Retrieved from http://www.wrap.org.uk/sites/files/ wrap/hhfdw-2012-main.pdf.pdf

Waste \& Resources Action Programme. (2014). Household food and drink waste: A product focus. Retrieved from http://www.wrap.org.uk/sites/files/wrap/Productfocused\%20report\%20v5_3.pdf

\section{Author Biographies}

Paul van der Werf, MSc, completed his PhD in the Department of Geography at Western University in London, Canada, in November, 2019. His research interests include the improved measurement of food waste and development of food waste reduction interventions. 
Jamie A. Seabrook, PhD, is an associate professor in the School of Food and Nutritional Sciences at Brescia University College, in London, Canada and his research focuses on socioeconomic status and health inequality.

Jason A. Gilliland, $\mathrm{PhD}$, is a professor of geography, pediatrics, and epidemiology and biostatistics at Western University in London, Canada. His research interests include community-based research and identifying interventions to public policy, programming, and neighborhood design to promote population health and quality of life. 